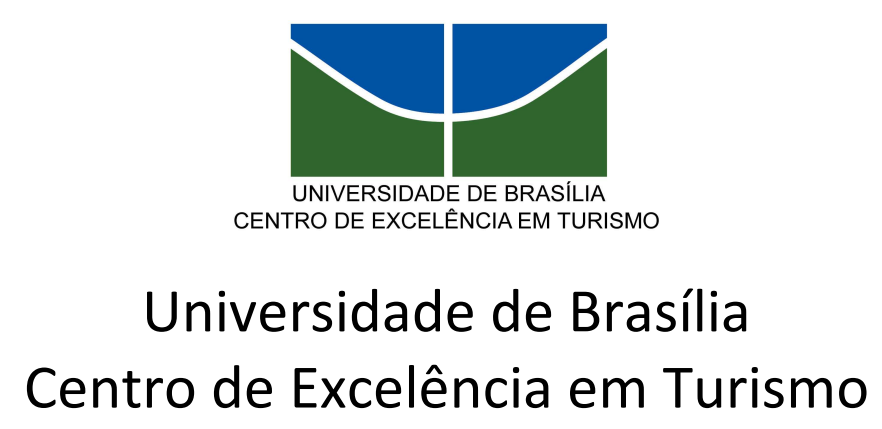

Qualidade em Alimentos

\title{
Avaliação das Condições Higiênico-sanitárias de Cozinhas Hospitalares da Asa Sul no Distrito Federal
}

\author{
Autor: Tatiana Serpa Guedes \\ Orientador (a): MSc. Lucianne Cardoso
}

Brasília, 2009. 


\author{
Universidade de Brasília \\ Centro de Excelência em Turismo
}

\title{
Avaliação das Condições Higiênico-sanitárias de Cozinhas Hospitalares da Asa Sul no Distrito Federal
}

Autor: Tatiana Serpa Guedes 


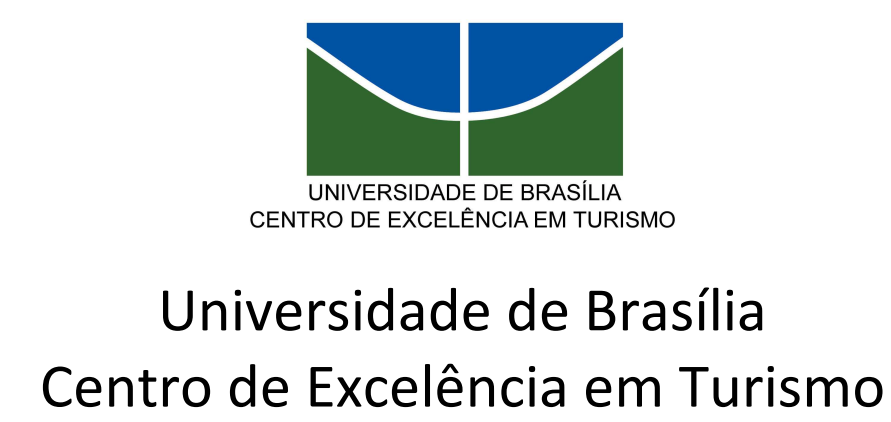

Pós-graduação Lato Sensu

Curso de Especialização em Qualidade em Alimentos

\title{
Avaliação das Condições Higiênico-sanitárias de Cozinhas Hospitalares da Asa Sul no Distrito Federal
}

\author{
Autor: Tatiana Serpa Guedes \\ Orientador (a): MSc. Lucianne Cardoso \\ Monografia apresentada ao Centro de \\ Excelência em Turismo - CET, da \\ Universidade de Brasília - UnB, como \\ requisito parcial à obtenção do grau de \\ Especialista em Qualidade em Alimentos.
}

Brasília, 2009. 
Guedes, Tatiana.

Avaliação das Condições Higiênico-sanitárias das Cozinhas Hospitalares da Asa Sul no Distrito Federal - Brasília, 2009.

Monografia (especialização) - Universidade de Brasília, Centro de Excelência em Turismo, 2009.

Orientador(a): Msc. Lucianne Cardoso 
UNIVERSIDADE DE BRASÍLIA

Centro de Excelência em Turismo

Pós-graduação Lato Sensu

Curso de Especialização em Qualidade de Alimentos

Autor: Tatiana Serpa Guedes

Aprovado por:

Orientador(a): Msc. Lucianne Cardoso

Msc. Manoel Silva Neto

Msc. Luiz Antônio Borgo

Brasília, 16 de janeiro de 2009. 


\section{RESUMO}

O presente estudo consistiu de uma avaliação das condições higiênico-sanitárias de $100 \%$ das cozinhas hospitalares da rede pública e privada da região da Asa Sul no Distrito Federal, de acordo com o formulário publicado e validado pela Agência Nacional de Vigilância Sanitária, a fim de verificar o cumprimento destes estabelecimentos as Boas Práticas de Fabricação e Procedimentos Operacionais padronizados conforme previsto por legislação. Os resultados da pesquisa apontaram para uma série de não-conformidades destes estabelecimentos, especialmente os de hospitais particulares, a quesitos e etapas na produção imprescindíveis a segurança e qualidade dos alimentos, alertando para a necessidade de implantação de um sistema de controle de qualidade mais rigoroso, começando, sobretudo pela real implementação das boas práticas de fabricação e dos procedimentos operacionais nestes locais.

Palavras-chave: Cozinhas Hospitalares, Boas práticas de Fabricação, Procedimentos Operacionais Padronizados. 


\begin{abstract}
The present study consisted of an assessment of hygiene conditions of $100 \%$ of both private and public hospital kitchens located in Asa Sul, Brasilia, according to the sanitary regulation form published by the Agência Nacional de Vigilância Sanitária, in order to evaluate their fulfillment and adequacy to food safety rules, mainly the requisites contained in Good Manufacturing manuals (GMP) and sanitary Standard Operating Procedure (SOP). The results in this research indicated that there were many food safety rules which were not followed in these kitchens, especially in private hospitals, alerting to the need of a real implementation of good manufacturing rules and standard operating procedure in these establishments.
\end{abstract}

Key-words: Hospital Kitchen, good manufacturing Practices, Standard Sanitization Operating Procedures. 


\section{LISTA DE TABELAS E FIGURAS}

Tabela 1 - Surtos alimentares registrados em hospitais de vários países.........................

Figura 1 - Contaminação dos Alimentos na Cadeia Alimentar...........................................5

Tabela 2 - Principais agentes bacterianos causadores de doenças de origem alimentar, todas classificadas de acordo com o risco e a difusão...................................................

Tabela 3 -Principais não-conformidades verificadas nas UANS hospitalares................26 


\section{SUMÁRIO}

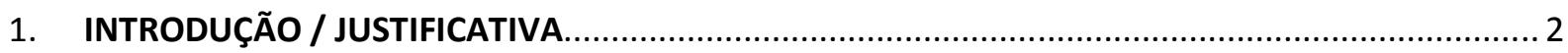

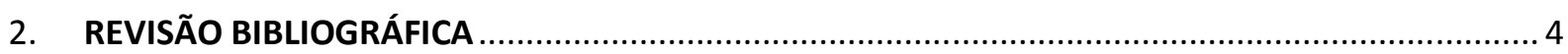

2.1 Doenças Transmitidas por Alimentos ..................................................................................... 4

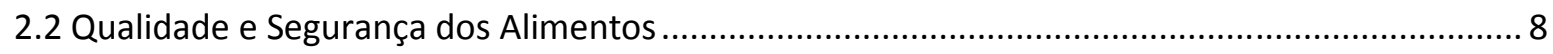

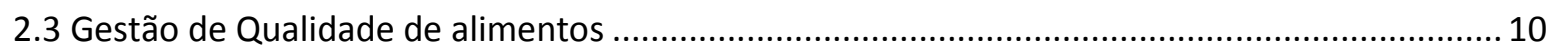

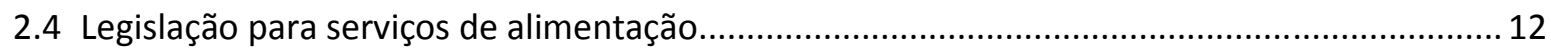

2.5 Alimentação e Nutrição em Unidades Hospitalares.................................................................. 15

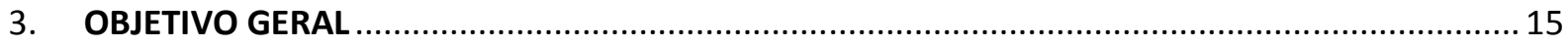

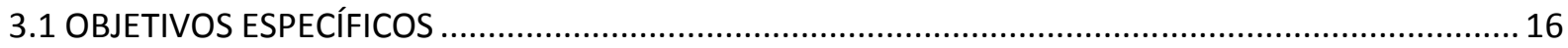

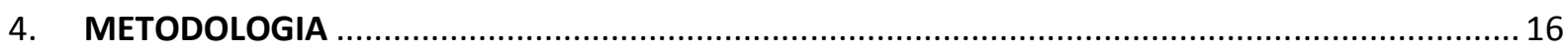

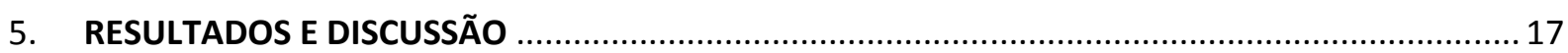

5.1 Instalações e Edificação do Estabelecimento ....................................................................... 17

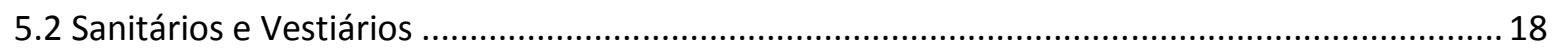

5.3 Higienização de instalações, equipamentos e utensílios ........................................................ 19

5.4 Controle Integrado de Vetores e Pragas Urbanas ............................................................... 19

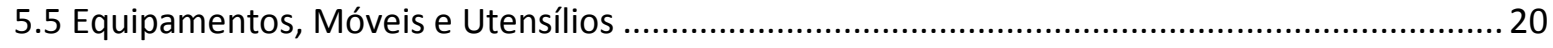

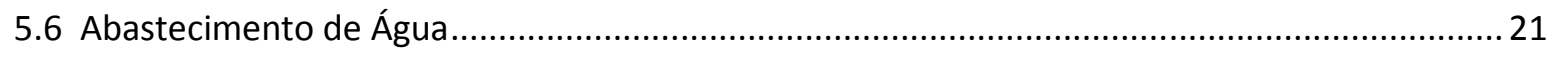

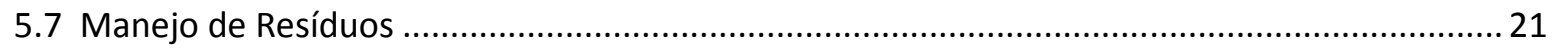

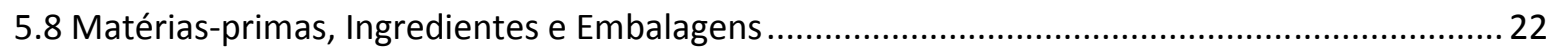

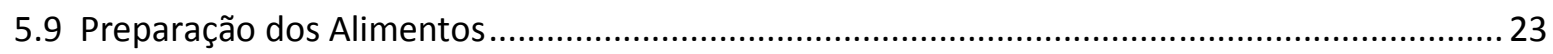

5.10 Manipuladores e Exposição ao Consumo do Alimento Preparado .............................................. 23

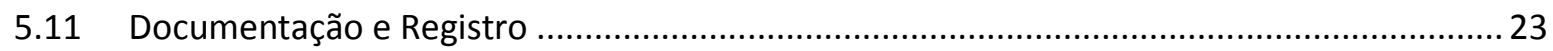

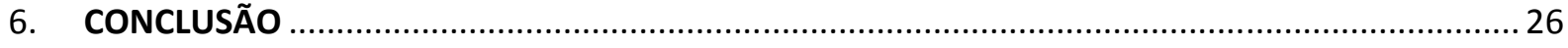

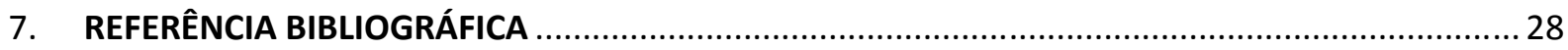

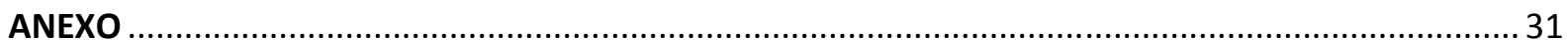

FORMULÁRIO DE LISTA DE VERIFICAÇÃO DE BOAS PRÁTICAS DE FABRICAÇÃO DA VIGILÂNCIA

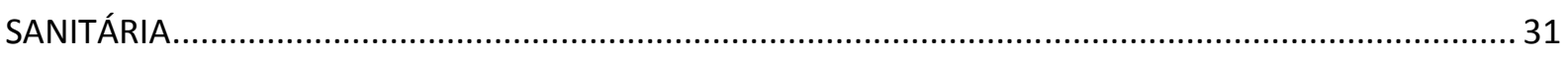




\section{INTRODUÇÃO / JUSTIFICATIVA}

As doenças transmitidas por alimentos se destacam como um dos fatores que mais contribuem para a morbidade nos países da América Latina e um dos maiores problemas de saúde pública no mundo contemporâneo (AKUTSU et al., 2005).

Só no ano de 2000, segundo registros do centro Nacional de Epidemiologia do Ministério da Saúde, ocorreram mais de 7000 casos de intoxicação por alimentos no Brasil (SANTOS, 2004).

Estatísticas mostram ainda que as doenças veiculadas por alimentos, sobretudo as de causa microbiana, estão aumentando em todo mundo independente do grau de desenvolvimento, condição socioeconômica e cultural do país (BADARÓ, AZEREDO, ALMEIDA, 2007).

É notório que o crescimento do número de surtos de toxinfecções alimentares tem acompanhado o aumento também dos serviços de alimentação impulsionados pelo desenvolvimento urbano e industrial a partir da segunda metade do século XX (AKUTSU et al., 2005; BODANESI, FATEL, SIMM, 2006).

Dentre estes serviços de alimentação destacam-se aqueles prestados em unidades hospitalares onde as dietas, além de terem o propósito de nutrir, também desempenham a importante função de auxiliar no tratamento e recuperação dos pacientes (SOUSA, CAMPOS, 2003).

Nestes estabelecimentos, uma vez que os alimentos são direcionados a pessoas enfermas e cuja imunidade pode estar debilitada, a responsabilidade com a inocuidade e segurança dos alimentos é maior ainda, podendo um surto de toxinfecção alimentar em ambiente hospitalar trazer consequências desastrosas e agregar risco de morte aos pacientes (NETO, 2006). 
No entanto, os efeitos de surtos alimentares em hospitais vão muito além do impacto na saúde e prognóstico dos pacientes. Do ponto de vista econômico, eles acarretam grandes gastos hospitalares e medicamentosos, além de trazer enormes perdas financeiras ao estabelecimento com o recolhimento e descarte de todo o estoque contaminado (ANVISA, 2003).

No decorrer dos anos, foram relatados em hospitais de diferentes países inúmeros casos de surtos alimentares (TABELA 1).

Tabela 1 - Surtos alimentares registrados em hospitais de vários países

\begin{tabular}{|c|c|c|c|}
\hline Local (Hospital) & Agente etiológico & $\begin{array}{c}\mathrm{N}^{\mathbf{0}} \text {. de Pessoas } \\
\text { acometidas }\end{array}$ & $\mathrm{N}^{\mathbf{0}}$. de Óbitos \\
\hline México & Salmonella enteridis & 155 & - \\
\hline Nova Zelândia & Norovirus & 65 & - \\
\hline Londres & Salmonella enteridis & 29 & 3 \\
\hline Alpes Suíços & $\begin{array}{c}\text { Salmonella } \\
\text { Thyphimurium }\end{array}$ & 29 & - \\
\hline Califórnia & Bacillus sp. & 40 & - \\
\hline Eslováquia & Salmonella enteridis & 16 & 15 \\
\hline Brasil & $\begin{array}{c}\text { Rotavirus, Bacillus } \\
\text { cereus, Clostridium } \\
\text { perfringens, } \\
\text { Staphylococcus aureus, } \\
\text { Samonella spp. }\end{array}$ & 48 & \\
\hline
\end{tabular}

Fonte: Neto, 2006 (pags. 9, 10)

Apesar de muito pouco conhecidos e divulgados, os surtos de origem alimentar sempre coexistiram com o ambiente hospitalar e sabe-se que uma de suas principais causas relaciona-se a falta de treinamento e implementação de boas práticas de higiene, resultando em uma equipe de manipuladores despreparados e deficientemente qualificados (SOUZA, CAMPOS, 2003). 
Diante deste cenário, a Agência Nacional de Vigilância Sanitária (ANVISA) estabeleceu normas e diretrizes preconizando a adoção das Boas Práticas de Fabricação em todos os estabelecimentos de produção e comercialização de alimentos e afins, com o intuito de reduzir a incidência dos surtos alimentares no país e garantir a saúde da população (BADARÓ, AZEREDO, ALMEIDA, 2007).

Apesar de não existir até o momento atual uma legislação específica para unidades de alimentação hospitalares, por serem locais em que é de extrema importância o controle de qualidade e segurança dos alimentos, é imprescindível a consonância destes estabelecimentos e seus serviços às boas práticas de fabricação e procedimentos operacionais padronizados como meio de assegurar a segurança de seus produtos e daqueles aos quais eles são destinados (NETO, 2006).

Assim sendo, o presente trabalho tem como objetivo verificar as condições higiênicosanitárias das unidades de alimentação dos hospitais públicos e privados da Asa Sul em Brasília pela avaliação da sua conformidade e adequação às diretrizes e normas de Boas Práticas de Fabricação (BPF) de acordo com a legislação vigente.

\section{REVISÃO BIBLIOGRÁFICA}

\subsection{Doenças Transmitidas por Alimentos}

Os microrganismos estão presentes em todo ambiente do convívio natural do homem. Eles são encontrados em locais como a água, ar, solo e ainda em seres vivos como plantas e animais. O próprio homem é hospedeiro de muitos microorganismos. Assim sendo, considerando os meios naturais como meios de onde são tirados os mais diversificados tipos de alimentos e o homem, como o responsável exclusivo pela sua manipulação, é fácil 
entender como é grande a probabilidade de sua contaminação por microrganismos (GIARETTA, FATEL, SIMM, 2006).

Não obstante, as cozinhas de estabelecimentos de alimentação, com seu pH neutro ou ligeiramente ácido, água, oxigênio, substratos e temperatura próxima de $35^{\circ} \mathrm{C}$, caracterizamse como ambientes extremamente favoráveis ao desenvolvimento de bactérias e outros microrganismos, que ao serem veiculados aos alimentos podem causar as doenças de origem alimentar (GIARETTA, FATEL, SIMM, 2006).

As doenças de origem alimentar são patologias causadas por agentes físicos, biológicos e/ou químicos quando veiculados aos alimentos. A causa mais comum dessas doenças é a contaminação microbiana, que ocorre principalmente pela falta de preparo e por negligência do manipulador de alimentos, irregularidade e más condições do espaço de trabalho e dos locais de armazenamento e, ainda, por falhas na limpeza de equipamentos, higiene pessoal e higiene operacional (FIGURA 1) (BADARÓ, AZEREDO, ALMEIDA, 2007).

Figura 1 - Contaminação dos Alimentos na Cadeia Alimentar

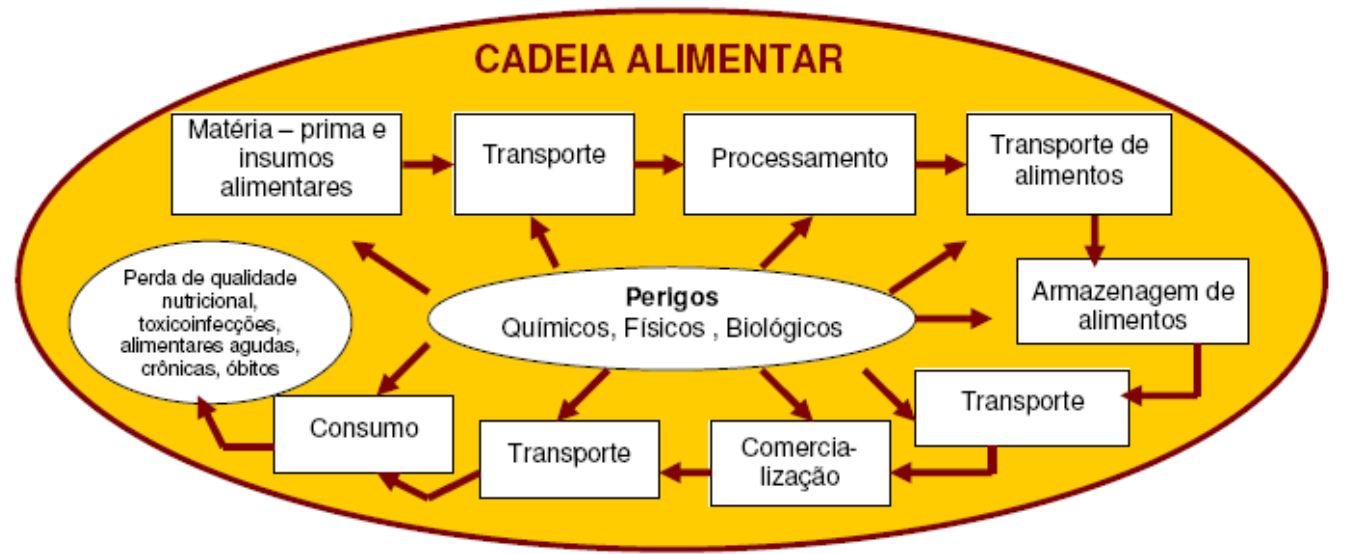

Fonte: SVS - Secretaria de Vigilância em Saúde - Boletim eletrônico epidemiológico (2005).

Considerando a amplitude do público atendido em serviços de alimentação, estas falhas na qualidade sanitária dos alimentos podem convergir para a ocorrência de surtos alimentares de pequena a maior amplitude, representando danos e gastos, algumas vezes 
irreversíveis tanto para os consumidores, quanto para a empresa e a saúde pública do país (ANVISA, 2003; SANTOS, 2004).

Segundo dados da Organização Mundial da Saúde (OMS), hoje, as doenças transmitidas por alimentos (DTAs) atingem indivíduos de todo o mundo, estimando-se que mais de $60 \%$ dos casos de toxinfecções alimentares sejam provenientes de alimentos servidos fora do ambiente doméstico (GIARETTA, FATEL, SIMM, 2006).

Os coliformes fecais, sobretudo a Escherichia coli, bactéria cujo habitat normal é o trato intestinal de todos os seres humanos e animais, destacam-se entre os microorganismos que mais comumente contaminam os alimentos através da transmissão direta ou indireta pelo homem, causando surtos alimentares (TABELA 2) (GIARETTA, FATEL, SIMM, 2006).

Desde a segunda metade do século XX, quando o desenvolvimento industrial, a urbanização, globalização e abertura de mercados impulsionaram os serviços de alimentação e setor de alimentação coletiva, aumentaram também a incidência das doenças transmitidas por alimentos, que se tornaram uma das maiores causas de morbi-mortalidade e problemas de saúde pública no mundo (AKUTSU et al., 2005).

No mundo, no período de 1997 a 2002, a Organização Panamericana de Saúde (OPAS) relatou 1.227.270 casos de doenças de origem alimentar. Apenas no ano de 2000, registraram-se mais de dois milhões de mortes por diarréia. Já no Brasil, entre 1993 e 2002, foram registradas 18.942 pessoas com toxinfecções alimentares (BADARÓ, AZEREDO, ALMEIDA, 2007).

Os custos dessas doenças são tão alarmantes quanto sua incidência. Estima-se que nos Estados Unidos há um gasto anual de até 37,1 bilhões de dólares, e no Brasil, em torno de 20 bilhões de dólares apenas com despesas diretas e indiretas decorrentes dessas enfermidades. Ainda assim, é muito provável que os gastos públicos sejam ainda muito maiores já que a maioria dos casos de doenças de origem alimentar não é notificada, e consequentemente a 
verdadeira dimensão do problema é desconhecida (BADARÓ, AZEREDO, ALMEIDA, 2007).

Tabela 2 - Principais agentes bacterianos causadores de doenças de origem alimentar, todas classificadas de acordo com o risco e a difusão.

\begin{tabular}{|c|c|}
\hline I - Muito perigosas & Veículo \\
\hline Clostridium botulinum & Alimentos enlatados e curados \\
\hline Salmenela typhi e $S$. paratyphi & Água, leite, verduras, produtos cárneos e lácteos \\
\hline Shigella dysenteriae & Água, verduras e saladas \\
\hline Vibrio cholerae & Água, alimentos diversos \\
\hline Brucella melitensis & Leite e queijo de cabra \\
\hline Clostridium perfringens tipo $\mathrm{C}$ & Carnes cozidas \\
\hline Vírus da hepatite infecciosa & Água, leite, saladas, verduras e mariscos \\
\hline \multicolumn{2}{|c|}{ II - Moderadamente perigosas de difusão extensa } \\
\hline Salmonella typhimurium & Carne de aves e ovos \\
\hline Shigella (Shigelose) & Águas e saladas \\
\hline Vibrio parahaemolyticus & Peixes e crustáceos \\
\hline Escherichia coli enteropatogênica & Carne e leite cru \\
\hline Staphylococcus betahaemolyticus & Leite e produtos lácteos crus, saladas e ovos \\
\hline \multicolumn{2}{|c|}{ III - Moderadamente perigosas de difusão limitada } \\
\hline Bacillus cereus & Arroz, pudins, derivados de cereais \\
\hline Brucella abortus & Leites e cremes \\
\hline Clostridium perfringens & Queijo fresco e carne cozida \\
\hline Staphylococcus aureus & Presuntos, pastéis, sobremesas e cremes \\
\hline
\end{tabular}

Fonte: Massaguer, 2006 (p. 26). 
Diante deste cenário atual e sua magnitude para a saúde pública, grandes esforços em todos os países têm sido mobilizados com o intuito de melhorar a qualidade e segurança dos alimentos (BADARÓ, AZEREDO, ALMEIDA, 2007).

\subsection{Qualidade e Segurança dos Alimentos}

A gestão com foco na qualidade total dos alimentos tem ganhado muito destaque nas empresas em nível mundial, devido ao aumento de aspectos como a competitividade, os níveis de produção, a exigência e demanda dos clientes e ainda o aparecimento de novas leis de defesa ao consumidor, todos fatores que têm movimentado uma série de organizações no ramo alimentício (SACCOL, 2007).

Qualidade não se trata de um processo com início e fim determinados, mas um conceito dinâmico e compromisso de toda a organização em obter incessantemente uma melhoria continuada de seus produtos e novos níveis de desempenho. A credibilidade de uma empresa de alimentos perante os consumidores, órgãos nacionais, internacionais e fiscalizadores está veiculada à qualidade e segurança oferecida pelo produto (SACCOL, 2007).

No setor de refeições coletivas a gestão de qualidade é fundamental para evitar ou diminuir as falhas no processo. Mesmo diante da amplitude de definições existentes acerca do que é qualidade, pode-se dizer que a qualidade nos serviços de alimentação engloba desde os aspectos intrínsecos ao alimento, como suas propriedades e atributos nutricionais e sensoriais, até um aspecto mais subjetivo em relação ao atendimento e satisfação da demanda e expectativa do cliente sobre a sua refeição e todo o processo nela envolvido (MOURA, 2004).

Em outras palavras, entende-se como qualidade em unidades de alimentação o fornecimento de alimentos íntegros, seguros e próprios para o consumo humano, que sejam de boa aceitação com relação ao sabor, apresentação e de acordo com as necessidades 
nutricionais e expectativa do cliente (SANTOS, 2004). Dentro deste contexto, e principalmente no caso das indústrias de alimentos, um dos fatores primordiais para a garantia da qualidade é a segurança alimentar (CARRIZO, 2005).

O conceito de segurança alimentar surgiu na Europa no final da Primeira Guerra Mundial. Tratava-se de um termo que representava a auto-suficiência de cada país em controlar o fornecimento de alimentos a partir de seus estoques estratégicos. Portanto, este termo estava relacionado fundamentalmente aos aspectos de disponibilidade, acesso e estabilidade na provisão de alimentos de um país (SILVA, AMARAL, 2004).

No início dos anos 70, a crise de escassez de alimentos fez com que o conceito de segurança alimentar ganhasse um destaque mundial. O Brasil adotou esse conceito com a I Conferência Nacional de Segurança Alimentar a partir de 1986 baseando-se no direito do cidadão de acesso a alimentos básicos, seguros, de qualidade e em quantidades suficientes (SILVA, AMARAL, 2004).

A segurança alimentar só adquiriu um caráter de segurança sanitária à partir de meados dos anos noventa, em decorrência das crises provocadas pelo surgimento da doença da "vaca louca" e da contaminação inicial de frangos na Bélgica pela presença de dioxinas em rações, em que a percepção dos consumidores sobre a qualidade dos alimentos alterou significativamente, tornando-os mais exigentes sobre a ação do Estado para vigilância e controle da qualidade sanitária dos alimentos (SILVA, AMARAL, 2004).

A partir de então, ganhou força o termo segurança de alimentos, que diferente do termo de segurança alimentar, que é mais abrangente, indica que o alimento não causa nenhum tipo de dano ao consumidor (SACCOL, 2007).

Assim, hoje, a segurança do alimento é um desafio atual e visa a oferta de alimentos livres de agentes que podem pôr em risco a saúde do consumidor. Por intermédio de condições higiênico-sanitárias adequadas, a segurança alimentar assegura a inocuidade do 
alimento, isto é, que ele esteja livre de contaminações químicas, físicas ou microbiológicas, não representando nenhum risco à saúde de quem o consome e garantindo, desse modo, a qualidade do produto final (ANVISA, 2003; SIMAS et al., 2005; CARRIZO, 2005).

Portanto, qualidade e segurança dos alimentos são fatores inseparáveis em toda a cadeia de produção dos alimentos, e estão diretamente relacionados aos sistemas e ferramentas de controle de qualidade, empregados nas empresas (CARRIZO, 2005; SACCOL, 2007).

\subsection{Gestão de Qualidade de alimentos}

Os programas de segurança alimentar, com o intuito de assegurar a qualidade dos alimentos, devem propiciar um controle de qualidade eficiente no processo de produção (SACCOL, 2007).

Atualmente, as empresas dispõem de vários instrumentos e métodos de controle e prevenção das doenças de origem alimentar, que se complementam ao acompanhar o alimento ao longo de toda a cadeia de alimentos, e, desta forma, garantem aos produtos alimentícios finais os padrões de excelência aceitáveis e esperados pelo consumidor e em concordância com os critérios determinados por legislação (AKUTSU et al., 2005; BADARÓ, AZEREDO, ALMEIDA, 2007).

Assim sendo, os instrumentos de controle de qualidade dos alimentos vão desde a identificação e estimativa de riscos e inconformidades que podem afetar a qualidade das refeições até a correção imediata dessas falhas e o monitoramento constante das condições operacionais, estruturais e de higiene de todas as etapas de produção dentro da Unidade de Alimentação (SANTOS, 2004).

Portanto, o controle de qualidade do alimento requer o monitoramento de todas as etapas de produção, desde a seleção de matéria-prima até o seu consumo, por meio de técnicas 
de implantação de sistemas de medidas preventivas e corretivas, que devem ser objetos de vigilância contínua (SACCOL, 2007).

Sabe-se que a detecção e correção rápida das falhas no processamento dos alimentos, bem como a adoção de medidas preventivas, são estratégias imprescindíveis para o controle higiênico-sanitário desses produtos, já que uma falha em qualquer parte da produção poderá comprometer e prejudicar o produto final. Portanto, as ferramentas de gestão funcionam como um meio eficaz para proteger os consumidores e garantir a qualidade dos alimentos (BADARÓ, AZEREDO, ALMEIDA, 2007).

Dentro deste contexto, destacam-se dentre as várias ferramentas de qualidade disponíveis, as Boas Práticas de Fabricação e os Procedimentos Operacionais Padronizados (SIMAS et al., 2005).

As Boas Práticas de Fabricação são constituídas de normas de procedimentos que são aplicadas a todas as unidades de alimentação, a fim de se alcançar um padrão de identidade do produto alimentício, pela garantia das condições higiênico-sanitárias no processamento do alimento (SANTOS, 2004; CARRIZO, 2005). Ou seja, é um conjunto de critérios e normas que descrevem formas ideais de fabricação na produção de alimentos, objetivando-se eliminar as possíveis fontes de contaminações do produto e assegurar a saúde do consumidor (GONÇALVES, SILVA, 2008).

Trata-se, portanto, de uma ferramenta que auxilia na avaliação preliminar das condições e não conformidades do estabelecimento de alimentos e de todas as etapas envolvidas no processo e fluxo de produção, permitindo traçar a partir deste ponto, ações corretivas que reduzem ou eliminam riscos físicos, químicos e biológicos do alimento (GENTA, MAURÍCIO,MATIOLI, 2005).

A adoção das boas práticas de fabricação resulta em inúmeros benefícios às empresas, como a redução de 15 até 40\% dos custos na produção (GONÇALVES, SILVA, 2008), 
redução de desperdícios e perdas, conquista de clientes e maior competitividade (SACCOL, 2007).

Os objetos das Boas Práticas de Fabricação se acercam de itens que vão desde as condições ambientais e de higiene do estabelecimento, instalações, equipamentos e utensílios, até os aspectos operacionais e pessoais de higiene dos manipuladores (SANTOS, 2004). Conjuntamente e não menos importante, as boas práticas de fabricação abordam ainda o treinamento e a reciclagem com os funcionários da área de produção, um quesito necessário, uma vez que a falta de profissionalização e conhecimento do setor dificulta a garantia da segurança alimentar e a implantação de boas práticas nas unidades de produção (CAVALLI, SALAY, 2007; GONÇALVES, SILVA, 2008).

Diversas pesquisas mostram que os resultados na produtividade dependem de investimentos em recursos humanos, uma vez que o aperfeiçoamento da qualidade depende basicamente do desempenho da equipe operacional e, portanto, a falta de investimentos, sobretudo no aspecto pessoal, torna impossível o desenvolvimento de técnicas necessárias ao sucesso da empresa (SACCOL, 2007).

Hoje, o sistema de Boas Práticas é um dos mais aceitos em gestão de qualidade e um dos que apresentam melhores resultados na obtenção de alimentos seguros, devido as suas principais vantagens de ser uma ferramenta atual, eficaz, de baixo custo e fácil execução (SACCOL, 2007).

\subsection{Legislação para serviços de alimentação}

A legislação sobre os alimentos iniciou-se em muitos países como uma tentativa de se evitar a comercialização de produtos defeituosos e fraudados. No entanto, com o passar do tempo, devido às novas exigências do mercado quanto a preocupação com a saúde do consumidor, a legislação foi sendo alterada e atualmente contempla outros aspectos da 
mercadoria, como a referente as suas condições higiênico-sanitárias e inocuidade (SACCOL, 2007).

A lei com requisitos básicos para higiene surgiu a partir do Decreto Lei número 986 de 1969, que abordava a necessidade de padrões de identidade e qualidade para os produtos. No intuito de complementar esta lei e garantir ainda mais a segurança da população, em 1990 a lei número 8078, por meio do Código do Consumidor, dispôs que todos os produtos colocados no mercado de consumo não apresentassem nenhum risco à saúde e segurança do consumidor (SACCOL, 2007).

Dois anos depois, acontecia a primeira reunião do Comitê do Codex Alimentarius para Sistemas de Inspeção e Certificação de Importações e Exportações de Alimentos, onde foram relatados que diversos governos no mundo optavam por métodos de garantia da qualidade baseados em códigos de Boas Práticas de Fabricação (BADARÓ, AZEREDO, ALMEIDA, 2007).

Após essa reunião, o incentivo e recomendação a adoção das Boas Práticas de Fabricação em todos os estabelecimentos de produção e comercialização de alimentos ganhou impulso e, no Brasil, foi preconizada pela primeira vez pela Portaria ${ }^{\circ} 1.428$ de 1993 . Nesta época ainda buscava-se uma mudança no paradigma referente ao foco do produto final para o foco sobre o controle de todos os processos de alimentos (BADARÓ, AZEREDO, ALMEIDA, 2007).

Mais tarde, no ano de 1997, foi publicada a Portaria $\mathrm{n}^{\circ} .326$ da Secretaria Nacional de Vigilância Sanitária, que estabeleceu o regulamento técnico sobre as Boas Práticas de Fabricação, tornando-as obrigatórias em todos os estabelecimentos de produção industrial de alimentos (BADARÓ, AZEREDO, ALMEIDA, 2007).

Posteriormente, para indicar as diretrizes de segurança dos alimentos, regulamentar e instruir as ferramentas de gestão de qualidade em estabelecimentos de alimentos surgiu a 
Resolução - RDC 216/04, uma das principais e mais conhecidas normas e resoluções para serviços de produção (CARRIZO, 2005; GENTA et al., 2005).

A Resolução RDC nº. 216, 15 de setembro de 2004 dispõe sobre o Regulamento Técnico de Boas Práticas para Serviços de Alimentação (SACCOL, 2007) e foi desenvolvida para atualizar e complementar a legislação geral, aplicando-se obrigatoriamente a todos os serviços de alimentação que realizam atividades desde a manipulação, até o armazenamento, distribuição e venda de alimentos preparados ao consumo, estando sujeito a sanções e multas todo e qualquer estabelecimento de alimentos que não estiverem em conformidade com ela (BADARÓ, AZEREDO, ALMEIDA, 2007).

Já em 2002, foram propostos pela RDC-275 os Procedimentos Operacionais padronizados, que trata de instruções sequenciais para a realização de operações rotineiras e específicas na manipulação de alimentos, tendo seu âmbito de aplicação obrigatório em todos os estabelecimentos onde há produção, fracionamento, armazenamento e transporte de alimentos industrializados. Apesar de serem parte das boas práticas de fabricação, dada sua importância, são estudados e frequentemente considerados separadamente, destacando-se por serem peças fundamentais para a organização, efetivação e eficácia dos procedimentos adotados pela empresa (NETO, 2006).

No entanto, tratando-se de unidades de alimentação hospitalares, a Vigilância Sanitária ainda não dispõe de normas de boas práticas de fabricação e procedimentos operacionais padronizados específicos a estes estabelecimentos. Porém, mesmo sendo a RDC 216/02 e a RDC 275/04 não aplicáveis e direcionadas a cozinhas hospitalares, elas ainda são as únicas normas que servem de ferramentas de qualidade em Boas Práticas e Procedimentos Operacionais Padronizados as cozinhas hospitalares diante da inexistência de outras e, portanto, em prática, muito úteis e indispensáveis para orientar estas unidades quanto ao controle e garantia da inocuidade dos alimentos. 


\subsection{Alimentação e Nutrição em Unidades Hospitalares}

Em uma unidade hospitalar a nutrição e alimentação têm como principal finalidade restaurar a saúde dos pacientes, servindo como um importante fator adjuvante ao tratamento médico. Desta forma, diferente dos demais serviços de alimentação que lidam com uma clientela saudável, as refeições em uma unidade hospitalar são destinadas a pessoas enfermas e debilitadas, cujo sistema imunológico pode encontrar-se um tanto comprometido e muito mais susceptível a infecções (SOUSA, CAMPOS, 2003). Assim sendo, não é difícil prever que a severidade das doenças alimentares causadas por um mesmo agente etiológico,em geral é muito maior em um paciente que nas pessoas sadias (NETO, 2006).

Hoje, é notório o fato de que uma das vias de infecção hospitalar são os alimentos contaminados, cuja principal causa é a falta da utilização de ferramentas de segurança alimentar e de controle de qualidade como as Boas Práticas de Fabricação e os Procedimentos Operacionais (NETO, 2006).

Assim sendo, considerando que os alimentos podem constituir uma fonte potencial de microorganismos no ambiente hospitalar e que as infecções alimentares são particularmente muito mais impactantes em pacientes hospitalizados do que em qualquer outro lugar, torna-se imprescindível a adoção de ferramentas de controle de qualidade, possibilitando desta forma a redução efetiva de riscos de surtos de origem alimentar em hospitais e a garantia da segurança dos pacientes (PINTO, CARDOSO, VANETTI, 2004).

\section{OBJETIVO GERAL}

Verificar as condições higiênico-sanitárias das unidades de alimentação dos hospitais públicos e privados da Asa Sul em Brasília. 


\subsection{OBJETIVOS ESPECÍFICOS}

- Avaliar a implementação do manual de Boas Práticas de fabricação e dos POPs em cada cozinha hospitalar da Asa sul;

- Fornecer à Vigilância local dados sobre as condições higiênico-sanitárias das cozinhas hospitalares da Asa sul no DF;

\section{METODOLOGIA}

Serão avaliadas neste estudo as condições higiênico-sanitárias de $100 \%$ das unidades de alimentação dos Hospitais da rede pública e privada localizadas na Asa Sul do Plano Piloto, na cidade de Brasília, DF. As unidades foram selecionadas com base no cadastro e área de cobertura da unidade de fiscalização da Vigilância Sanitária localizada na Asa Sul e o período de coleta nos meses de Dezembro de 2008 e Janeiro de 2009.

A coleta de dados para a avaliação da implementação das Boas Práticas de Fabricação e dos Procedimentos Operacionais padronizados nos estabelecimentos em estudo foi realizada mediante observação e aplicação de um formulário em forma de lista de verificação publicado e validado pela Vigilância Sanitária do país, baseado na Resolução - RDC - 216/04 e de Boas Práticas de Fabricação e RDC- 275/02 - Procedimentos Operacionais Padronizados para estabelecimento de alimentos (ANEXO).

Os itens de boas práticas avaliados foram referentes a edificação e instalações; sanitários; higienização de instalações; equipamentos e utensílios; controle de pragas e vetores; equipamentos, móveis e utensílios; abastecimento de água; manejo de resíduos; matérias, ingredientes e embalagens; preparo de alimentos; exposição do alimento para consumo; manipuladores, documentação e registro. Dos POPs, foram avaliados os de 
higienização das instalações, controle da potabilidade de água, higiene e saúde dos manipuladores, manejo de resíduos, manutenção preventiva e calibração de equipamentos, controle integrado de pragas e seleção de matérias- primas.

Para a tabulação dos dados obtidos foi utilizado o programa do Microsoft Excel 2003 e a discussão dos resultados teve foco apenas nas não-conformidades mais freqüentes e, portanto, com maior relevância ao estudo.

\section{RESULTADOS E DISCUSSÃO}

\subsection{Instalações e Edificação do Estabelecimento}

Neste quesito, observou-se nas Unidades de Alimentação Hospitalares estudadas uma série de inadequações, dentre elas problemas e limitações no fluxo ordenado e espaço físico da unidade. Em $37.5 \%$ das cozinhas, por exemplo, o dimensionamento mostrou-se incompatível com a demanda da produção, causando tumulto e desordem durante o preparo e distribuição das refeições. Em consequência disto, as diferentes áreas de atividade (prépreparo, preparo, cozinha dietética, cozinha geral, armazenamento) mesmo separadas por

meios físicos, mantinham-se muito próximas umas das outras acarretando em um fluxo cruzado com risco de contaminação dos diferentes alimentos manipulados.

Outra inconformidade verificada nestes estabelecimentos foi relativa à qualidade de seu revestimento estrutural. Em $75 \%$ das unidades analisadas, os pisos, paredes e tetos encontravam-se em estado de conservação ruim e apresentavam ainda rachaduras e trincas. Em uma das cozinhas a situação ainda era mais crítica devido ao revestimento de todas as paredes por tinta permeável, totalmente inadequada e não resistente a processos de lavagem e higienização. 
As inadequações em relação ao uso de telas, fechamento automático das portas das cozinhas hospitalares e sistema de iluminação também foram comuns. De 37.5\% das unidades que apresentavam uso incorreto de telas, $25 \%$ não as usavam em todas as janelas e aberturas da unidade e $12.5 \%$ não apresentavam todas as telas passíveis de remoção para lavagem e higienização.

Já referente ao item sobre as condições de fechamento das portas da área de preparação de alimentos e iluminação, em torno de $37.5 \%$ das cozinhas estudadas não apresentavam portas dotadas de fechamento automático, facilitando a entrada de pragas e vetores também por este meio, $12.5 \%$ das cozinhas apresentaram luminosidade insuficiente para as atividades de preparo dos alimentos e $50 \%$ das unidades foram reprovadas no quesito de proteção das luminárias contra explosão.

Além disso, apesar de todas as unidades apresentarem em seu espaço físico lavatórios exclusivos para lavagem das mãos, em 50\% deles os lavatórios não estavam posicionados em locais estratégicos, mas um tanto distante dos manipuladores, tornando questionável sua real eficiência.

\subsection{Sanitários e Vestiários}

Neste grupo avaliado, o estudo mostrou que em $12.5 \%$ das unidades, os vestiários dos manipuladores de alimentos eram improvisados apenas com tapumes de obra, mostrando além de precariedade um estado de organização ruim e quase nenhuma condição de ser utilizado como tal propósito. Do mesmo modo, em $75 \%$ das unidades, as instalações sanitárias não eram dotadas de fechamento automático e em $62 \%$ os coletores de resíduos dos sanitários eram mantidos sem tampas e pedais. 


\subsection{Higienização de instalações, equipamentos e utensílios}

De uma forma geral, pôde-se observar que, apesar de todas as unidades alegarem proceder corretamente com a lavagem e sanitização das unidades e de todos seus equipamentos e bancadas, $62 \%$ dos estabelecimentos não tinham como comprovar a freqüência, o modo e a eficácia com que eram realizados estes procedimentos. De fato, estas unidades não realizavam nenhum controle da diluição, tempo de contato e aplicação dos produtos saneantes durante os procedimentos de higienização. Além disso, 25\% delas sequer tinham procedimentos operacionais padronizados (POP) para higienização de instalações e equipamentos na unidade e outros $37.5 \%$, apesar de terem o POP na unidade, dispunham de informações incompletas, dificultando seu entendimento, interpretação e execução.

Ainda no quesito de higienização de instalações, uma unidade de alimentação hospitalar (12.5\%) mantinha em seu quadro os mesmos funcionários de manipulação dos alimentos para realizar a tarefa operacional de higienização ambiental, de utensílios e equipamentos, aumentando o risco de contaminações dos alimentos naquele local.

\subsection{Controle Integrado de Vetores e Pragas Urbanas}

Quanto ao controle integrado de vetores e pragas, foi possível observar que a grande maioria das cozinhas hospitalares não estava totalmente livre de vetores e pragas urbanas como deveria. Apesar de algumas unidades estudadas serem dotadas de telas protetoras e apresentarem portas com fechamento automático, $50 \%$ dos estabelecimentos mantinha as portas abertas durante toda a etapa de produção, possivelmente desta forma facilitando o acesso de vetores, principalmente moscas. Não obstante, em $37.5 \%$ das unidades, os laudos e certificação de serviço de controle de pragas também não se faziam presentes, não havendo como comprovar mediante a documentação sua periodicidade de execução. Além disso, em $87.5 \%$ das unidades, não havia qualquer indício de monitoramento e registro da presença de 
pragas e suas formas de prevenção, uma prática frequentemente confundida pelos responsáveis com a etapa de aplicação de produtos químicos na unidade por uma empresa terceirizada.

\subsection{Equipamentos, Móveis e Utensílios}

Neste grupo de itens estudados, as inconformidades mais observadas foram referentes à falta de alguns equipamentos indispensáveis nas unidades e o mal estado de conservação de outros. Em 37.5\% dos estabelecimentos, não havia equipamentos em quantidades suficientes, sobretudo refrigeradores, câmaras, freezers e bancadas de distribuição, comprometendo todo o procedimento seguro de armazenamento e parte do processo de manuseio dos alimentos.

Das unidades que dispunham de freezers, câmaras e refrigeradores, 37.5\% continham equipamentos muito antigos, em inadequado funcionamento e mal estado de conservação, e ainda, sem medidores de temperatura e planilhas de registro de monitoramento de temperatura e calibração programada de utensílios e equipamentos devidamente preenchidas. Em uma das unidades, por exemplo, o mal estado de conservação de uma das câmaras resultou na exposição das carnes em caixas de polietileno para descongelamento sob temperatura ambiente durante horas e sem nenhum controle de temperatura, colocando em risco a qualidade do alimento.

Em outro caso, não dispondo de bancadas suficientes para a montagem das legumeiras que saíam para os quartos de internação, a unidade passou a ter estas mesmas legumeiras montadas de improviso em cima de um freezer disposto no centro da cozinha, mais uma vez sem nenhum controle de higiene e colocando em risco a salubridade do produto. 


\subsection{Abastecimento de Água}

Neste quesito, pôde-se verificar que todas as unidades recebiam água potável da Companhia de Saneamento Ambiental do Distrito Federal. No entanto, 50\% das unidades não tiveram como apresentar laudos para comprovar a potabilidade da água. Isso devido ao fato deste controle ser realizado por outros setores do hospital, o que não significava, portanto que essas análises não fossem realizadas. Além disso, observou-se também que $25 \%$ das unidades não dispunham de procedimento operacional, apesar da higienização da caixa d'água não ser terceirizada.

\subsection{Manejo de Resíduos}

Quanto ao manejo de resíduos, o estudo mostrou que em $37.5 \%$ das unidades, não havia local separado para saída de lixo e recebimento de mercadorias. Neste caso, todas estas cozinhas remediavam a situação com o manejo de lixos em horários diferentes do horário de recebimento de mercadoria. No entanto, em um destes estabelecimentos, a área externa da cozinha não dispunha de local próprio e isolado para a estocagem dos resíduos descartados, se transformando em um meio de atração de vetores.

Além disso, em $37.5 \%$ das cozinhas hospitalares, mesmo os coletores de lixos com pedais mantinham-se abertos dentro da área de produção ou então não funcionavam adequadamente, tornando-se um foco em potencial de contaminação de alimentos.

Neste item também pôde ser verificado um número alarmante de $87.5 \%$ de unidades que não apresentaram os POPS correspondentes e os registros de monitoramento desta etapa, apesar dos responsáveis alegarem que um controle e preocupação com a freqüência e horário de saída eram realizados. 


\subsection{Matérias-primas, Ingredientes e Embalagens}

Em relação a este quesito, houve um elevado índice de inconformidades, com destaque principalmente para as embalagens, identificação dos produtos manipulados e armazenamento. Em $62 \%$ das cozinhas hospitalares, havia diversos alimentos e ingredientes sem identificação ou com rótulos incompletos dificultando a consulta de informações de validade e reconhecimento do produto. Em três destes casos $(37.5 \%)$ foi verificada a presença de produtos altamente perecíveis como a salsicha e frango, há meses já vencidos e que ainda não tinham sido descartados.

Em 50\% das unidades foram vistas também irregularidades com o invólucro dos produtos abertos como, por exemplo, carnes congeladas sem embalagem, peixes congelados embalados em sacos impróprios para congelamento e armazenamento de alimentos de diferentes grupos, entre eles carnes, poupa e verduras, num mesmo freezer.

O almoxarifado também foi um setor que apresentou alguns problemas. Conforme observado em $25 \%$ das unidades estudadas, nele foram encontrados objetos não condizentes com o local e em desuso, principalmente caixas de papelão e descartáveis e ainda alimentos dispostos sobre estrados de madeira, ao invés de polietileno. Em uma destas unidades, dentro do almoxarifado foram observados problemas referentes ainda a uma abertura externa não telada, produtos abertos que deveriam ser mantidos sob refrigeração e a presença de materiais tóxicos, entre eles baldes de tintas para parede.

Nas operações de recebimento de matéria-prima, além de algumas unidades não terem uma área específica e preparada para a recepção de mercadorias, um total de $62 \%$ não tinham sequer planilhas de controle para a recepção de alimentos, controle de temperatura e condições de transporte, um indicativo da falta e falha no padrão de qualidade na seleção e aceitação dos produtos pelas unidades. 


\subsection{Preparação dos Alimentos}

Em 37.5\% das Unidades estudadas, verificou-se que o controle do tratamento térmico pelo binômio tempo-temperatura não era realizado e nem registrado por funcionários, não se tendo certeza se as temperaturas de cocção e reaquecimento de alimentos utilizadas eram suficientes para assegurar sua qualidade higiênico-sanitária. O mesmo pôde ser observado em relação ao controle de qualidade e descarte de óleos usados em frituras, verificado que em 50\% das unidades não havia aferição de temperatura ou instrução dos funcionários objetivando-se evitar que o óleo aquecido ultrapasse seu limite térmico superior recomendado de 180 graus e constitua uma fonte de contaminação química ao alimento preparado.

\subsection{Manipuladores e Exposição ao Consumo do Alimento Preparado}

Neste quesito, uma das principais inconformidades foi referente ao controle de troca e higiene de uniformes, que na maioria das unidades (75\%), se dava apenas de forma visual e sem nenhum tipo de registro. Em uma destas unidades, o problema quanto ao uso do uniforme ainda era mais preocupante, devido a ausência de uniformes próprios, EPI's, luvas e máscaras disponíveis para uso individual dos funcionários. Além disso, em 25\% das unidades estudadas nenhum controle de saúde dos funcionários era realizado e registrado.

Outro problema comum ocorreu em 50\% das cozinhas, onde os visitantes eram requisitados a usarem apenas toucas na entrada como requisito de higiene e saúde, sem a exigência e atenção para o uso do jaleco.

\subsection{Documentação e Registro}

Neste quesito, foi observado que todos os estabelecimentos eram dotados de manual de boas práticas. No entanto, o mesmo não se pôde verificar em relação aos procedimentos operacionais padronizados e das diversas falhas referentes aos registros em planilhas e 
implementação do manual. Em 37.5\% dos casos, por exemplo, os manuais encontravam-se desatualizados e incompatíveis com as atividades locais.

Em relação aos procedimentos operacionais padronizados (POPS), 37.5\% das unidades estavam com eles incompletos e uma unidade nem sequer tinha ainda os procedimentos operacionais implantados. Dos POPS analisados, o que mais apresentou problemas foi o de higienização de instalações, equipamentos e móveis e higienização das mãos. Em 37.5\% das unidades visitadas, por exemplo, o POP de higienização de instalações e equipamentos não continha as informações referentes à natureza da superfície a ser higienizada e princípio ativo dos produtos. Igualmente, em 3 unidades visitadas (37.5\%), nos lavatórios exclusivos para higienização das mãos não existiam cartazes de orientação sobre a correta lavagem e anti-sepsia das mãos para os funcionários.

Para dificultar ainda mais o controle de qualidade e a implementação das boas práticas nas unidades, 75\% das cozinhas não mantinham seus POPS disponíveis e acessíveis aos funcionários para consulta em caso de dúvidas, e ainda não adotavam os registros e/ou controles em planilhas adequadamente preenchidas referentes ao acompanhamento de saúde e higiene dos funcionários, manutenção e calibração programada e periódica de utensílios e equipamentos, operações de limpeza, higiene e diluição de produtos, controle do binômio tempo- temperatura de aquecimento, temperatura de armazenamento e transporte, controle de qualidade na recepção de mercadorias e treinamentos periódicos de capacitação de funcionários. Além disso, das poucas planilhas de controle de temperatura que foram encontradas em algumas unidades $(25 \%)$, as mesmas não tinham orientações referentes a medidas corretivas e encontravam-se incompletas.

Assim sendo, quesitos importantes para a garantia da segurança do alimento não foram atendidos, principalmente em cozinhas de hospitais privados, conforme previsto por legislação e conforme o esperado para as unidades de alimentação como estas, que lidam com 
grupos de risco. Foram encontradas em grande parte das cozinhas (TABELA 3) sobretudo as faltas e falhas de grande parte das documentações e registros, que puderam muito pouco comprovar a execução dos objetivos proposto pelo manual de boas práticas, tornando duvidosa e questionável sua real implementação e eficácia nestes estabelecimentos.

Tabela 3 -Principais não-conformidades verificadas nas UANS hospitalares

\begin{tabular}{|c|c|c|}
\hline Categorias & Não-conformidades & Percentual \\
\hline \multirow{6}{*}{$\begin{array}{c}\text { INSTALAÇÕES E } \\
\text { EDIFICAÇÃO DA ÁREA DE } \\
\text { PRODUÇÃO }\end{array}$} & Dimensionamento incompatível e fluxo cruzado & $37.5 \%$ \\
\hline & Estado ruim de conservação - pisos, tetos, paredes & $75 \%$ \\
\hline & Inexistência de telas removíveis & $37.5 \%$ \\
\hline & Portas sem fechamento automático & $50 \%$ \\
\hline & Portas com fechamento automáticas mantidas abertas & $50 \%$ \\
\hline & Luminárias sem proteção contra explosão & $50 \%$ \\
\hline \multirow{2}{*}{ SANITÁRIOS } & Portas sem fechamento automático & $75 \%$ \\
\hline & Coletores sem tampas e pedais & $62 \%$ \\
\hline \multirow{2}{*}{$\begin{array}{l}\text { HIGIENE DE INSTALAÇÕES E } \\
\text { EQUIPAMENTOS }\end{array}$} & Falta de planilhas de registro & $62 \%$ \\
\hline & Ausência de POPS & $25 \%$ \\
\hline \multirow{2}{*}{ CONTROLE DE PRAGAS } & Sem laudo e certificação de serviço & $37.5 \%$ \\
\hline & Procedimento Operacional Padronizado & $87.5 \%$ \\
\hline LIMPEZA DE CAIXA D'ÁGUA & Sem laudo e certificação de serviço & $50 \%$ \\
\hline \multirow{2}{*}{$\begin{array}{c}\text { EQUIPAMENTOS, MÓVEIS E } \\
\text { UTENSÍLIOS }\end{array}$} & Quantidades insuficientes de equipamentos & $37.5 \%$ \\
\hline & Equipamentos em ruim estado de conservação & $37.5 \%$ \\
\hline \multirow{3}{*}{ MANEJO DE RESÍDUOS } & Mesmo local de recebimento de mercadorias & $37.5 \%$ \\
\hline & Coletores abertos ou sem funcionamento adequado & $37.5 \%$ \\
\hline & Procedimento Operacional & $87.5 \%$ \\
\hline \multirow{5}{*}{$\begin{array}{l}\text { MATÉRIA-PRIMA, } \\
\text { INGREDIENTES E } \\
\text { EMBALAGENS }\end{array}$} & Alimentos sem identificação adequada & $62 \%$ \\
\hline & Produtos vencidos & $37.5 \%$ \\
\hline & Invólucro inadequado & $\mathbf{5 0} \%$ \\
\hline & Armazenamento de diferentes alimentos juntos & $50 \%$ \\
\hline & Falta de padrão e controle de qualidade na recepção & $65 \%$ \\
\hline \multirow{2}{*}{$\begin{array}{l}\text { PREPARAÇÃO DOS } \\
\text { ALIMENTOS }\end{array}$} & Controle de temperatura de aquecimento do alimento & $37 . \%$ \\
\hline & Controle de temperatura dos óleos & $50 \%$ \\
\hline \multirow{3}{*}{$\begin{array}{l}\text { MANIPULADORES E } \\
\text { VISITANTES }\end{array}$} & Falta de controle de uniformes & $75 \%$ \\
\hline & Falta de controle de saúde & $25 \%$ \\
\hline & Visitantes sem cumprimento de requisitos de higiene & $50 \%$ \\
\hline
\end{tabular}




\begin{tabular}{|l|c|c|}
\hline \multirow{2}{*}{$\begin{array}{c}* \\
\text { DOCUMENTAÇÃO E } \\
\text { REGISTRO }\end{array}$} & Manual de boas práticas incompatível e desatualizado & $\mathbf{3 7 . 5 \%}$ \\
\cline { 2 - 3 } & Indisponibilidade de POPS aos funcionários & $75 \%$ \\
\cline { 2 - 3 } & Presença de POPS incompletos & $\mathbf{3 7 . 5 \%}$ \\
\hline
\end{tabular}

\section{CONCLUSÃo}

Os sistemas de gestão de qualidade, como as boas práticas de fabricação, conforme previstos pela legislação, pressupõem uma série de etapas que vão desde o planejamento e execução, até o monitoramento e correção das não-conformidades apontadas pelo monitoramento.

Para que o alimento se torne fonte de saúde ao consumidor, e nos casos das unidades hospitalares, ao pacientes, é imprescindível que haja um controle de qualidade rigoroso e sistemático de todas as etapas do processamento do alimento, seja ele matéria-prima seja ele produto acabado, para a garantia de sua inocuidade e segurança.

Considerando o fato de que a ingestão de alimentos contaminados é uma das principais vias de infecção hospitalar, a manutenção de sua qualidade torna-se um fator imprescindível, pois pode minimizar, senão evitar, surtos de origem alimentar que em um ambiente como o de um hospital poderiam causar riscos de morte aos internados que, na maioria das vezes, já encontram-se com a imunidade e estado de saúde comprometidos.

Conforme verificado neste trabalho, houve uma porcentagem alta de falhas de obediências aos princípios básicos de higiene nas unidades de alimentação hospitalares estudadas, destacando-se na parte estrutural principalmente problemas com dimensionamento e fluxo impróprios, estado ruim de conservação das unidades, ausência de portas com fechamento automático e proteção contra explosão de luminárias. 
Foi observada também a falta de equipamentos adequados e em bom funcionamento, principalmente os de conservação, um grande descaso com o monitoramento e registro em planilhas de controle, principalmente referentes à higienização de instalações e equipamentos, recepção de mercadoria, manejo de resíduos, controle de pragas e monitoramento de temperatura, nas mais diversas etapas de produção. A falha no cumprimento dos POPS, bem como no treinamento e reciclagem periódica dos funcionários, também foram verificadas, chamando ainda mais atenção para as lacunas e riscos ainda existentes nos sistemas de qualidade dentro das unidades de alimentação hospitalares.

Estas não-conformidades, observadas principalmente nas cozinhas de hospitais privados, corroboram os dados encontrados por NETO (2006) e apontam para o baixo nível de implementação das boas práticas de fabricação e POPS, que colocam em risco não só toda a qualidade da produção, mas principalmente a saúde daqueles para quem os alimentos são, por fim, destinados.

Assim sendo, conclui-se que as condições higiênico-sanitárias de grande parte das unidades de alimentação hospitalares em estudo, mostraram-se inadequadas, mesmo diante da obrigatoriedade prevista por lei e mesmo diante da grande responsabilidade de um serviço prestado a um grupo de risco. Estes dados, portanto, alertam para a necessidade de implantação de um sistema de controle mais rigoroso e de maior comprometimento com a qualidade dos alimentos manipulados em ambiente hospitalar, começando sobretudo pela implementação das boas práticas de fabricação, dos procedimentos operacionais, do registro das etapas monitoradas e uma maior fiscalização dos órgãos responsáveis nestes ambientes como um meio de coerção para estas mudanças. 


\section{REFERÊNCIA BIBLIOGRÁFICA}

ANVISA, Projeto para implantação de boas práticas de fabricação em restaurantes comerciais das principais cidades turísticas do estado de Goiás, Goiânia, 2003. Disponível em: www.anvisa.goias.gov.br/produtos/cidturisticas.pdf. Acesso em: 08/09/08

AKUTSU, R.C.; BOTELHO, R.A.; CAMARGO, E.B.; SÁVIO, K.E.O.; ARAÚJO, W.C. Adequação das boas práticas de fabricação em serviços de alimentação. Revista de Nutrição, Campinas, v. 18, n. 3, p. 419-27, maio/jun., 2005.

BADARÓ, Andréia C.; AZEREDO, Raquel M.; ALMEIDA, Marta Elisa. Vigilância Sanitária de Alimentos: Uma Revisão. Revista Digital de Nutrição: Nutrir Gerais, Unileste , MG, V. 1 N. 1 - Ago./Dez. 2007.

CARRIZO, Alberto. Proposta para integrar os sistemas de gestão de qualidade, das boas práticas de fabricação e da APPCC em uma pequena empresa de suco de frutas. Dissertação (Mestrado), Universidade Federal de São Carlos, 2005.

CAVALLI, Suzi ; SALAY, Elizabete. Gestão de pessoas em unidades produtoras de refeições comerciais e a segurança alimentar, Revista Nutrição, Campinas, 20(6):657-667, Nov/ Dez, 2007.

GENTA, Tânia M.S.; MAURÍCIO, Angélica; MATIOLI, Graciette. Avaliação de boas práticas de fabrição através de checklist aplicado em restaurantes self-service da região central de Maringá, Estado do Paraná, Revista Health Science, Maringá, Vol. 2,7 n.2, p. 151$156,2005$.

GIARETTA, Flávia R; FATEL, Elis C. S.; SIMM, Kelen C. B., Avaliação Microbiológica e higiênico-sanitária em uma panificadora do município de Realeza-PR.Disponível em: www.fag.edu.br/tcc/2006/Nutricao/(AVALIA_307AO\%20MICROBIOLOGICA\%20E\%20H IGIENICO-SANITARIA\%20EM\%20UMA\%20PA.pdf

Acesso em: 22/11/08

GONÇALVES , Priscila M.; SILVA, Humberto F. Boas Práticas de fabricação - BPF; Aplicação em uma indústria de embalagens alimentícias, São Paulo. Revista de Administração da FATEA, Faculdades Integradas Teresa D'Ávila - Edição 2008. Disponível em: http://www.fatea.br/raf/pdf/artigo04_pdf.pdf. Acesso em: 07/11/08.

Lei Federal $n^{0} .8078$ de 11/09/1990. Dispõe sobre a proteção do consumidor e dá outras providências. Diário Oficial da União, Brasília. 1990a. 
MASSAGUER, P.R. Microbiologia dos processos alimentares. São Paulo: Livraria Varela. 2006. 258p.

Ministério da Saúde. Portaria $\mathrm{n}^{\mathrm{o}}$. 1.428, de 26 de novembro de 1993. Aprova o regulamento técnico para inspeção sanitária de alimento; diretrizes para o estabelecimento de Boas Práticas de Produção e de Prestação de Serviços na Área de Alimentos; e regulamento técnico para o estabelecimento de padrão de identidade e qualidade para serviços e produtos na área de alimentos. Brasília, 1993.

Ministério da Saúde. Secretaria de Vigilância Sanitária. Portaria $n^{\circ} .326$, de 30 de julho de 1997. Regulamento Técnico sobre as Condições Higiênico-Sanitárias e de Boas Práticas de Fabricação para Indústrias de Alimentos. Brasília, 1997.

Ministério da Saúde. Agência Nacional de Vigilância Sanitária. Resolução-RDC nº . 275, de 21 de outubro de 2002. Dispõe sobre Regulamento Técnico de Procedimentos Operacionais Padronizados aplicados aos Estabelecimentos Produtores/Industrializadores de Alimentos e a Lista de Verificação das Boas Práticas de Fabricação em Estabelecimentos Produtores/Industrializadores de Alimentos. Brasília, 2002.

Ministério da Saúde. Agência Nacional de Vigilância Sanitária. Resolução-RDC nº . 216, de 15 de setembro de 2004. Dispõe sobre Regulamento Técnico de Boas Práticas para Serviços de Alimentação. Brasília, 2004.

MOURA, Thais L. Determinantes de qualidade em serviços de alimentação:o caso das empresas de refeições coletivas. In: XXIV ENGEP - Encontro Nacional de Engenharia de Produção, Florianópolis, SC, Nov. 2004.

NETO, Manoel S. Diagnóstico Situacional da Utilização das Ferramentas de Segurança na Produção de Alimentos nas Cozinhas das Unidades de Alimentação e Nutrição dos Hospitais de Brasília-DF. Dissertação (Mestrado), Universidade de Brasília, Distrito Federal, 2006.

PINTO, Uelinton M., CARDOSO, Rodrigo R., VANETTI Maria Cristina D. Detecção de Listeria, Salmonella e Klebsiella em serviço de alimentação hospitalar. Revista de Nutrição, Campinas, 17(3):319-326 jul./set., 2004.

SACCOL, Anna Lúcia F. Sistematização de ferramenta de apoio para boas práticas em serviços de alimentação. Dissertação (Mestrado), RS, Santa Maria, Brasil, 2007.

SANTOS, Deise M. Segurança Alimentar: Aspectos técnicos e sócio-culturais sobre riscos potenciais na rede hoteleira de Florianópolis. Dissertação (Mestrado), Universidade do Vale do Itajaí, Balneário Camboriú, 2004.

SILVA, Valquíria da; AMARAL, Ana Maria P. Segurança Alimentar, Comércio Internacional e Segurança Sanitária. Revista Informações Econômicas, SP, v.34, n.6, jun. 2004.

SIMAS, Karina N. et al. Aprimoramento do manual de boas práticas de fabricação e dos procedimentos operacionais padronizados do restaurante do centro de atividade de Florianópolis do serviço social do comércio, Santa Catarina, Set/ 2005.

Disponível em: www.sepex.ufsc.br/anais_5/trabalhos/32.html. Acesso em: 19/09/08 
SOUZA, Lúcia C., CAMPOS, Gizella D., Condições higiênico-sanitárias de uma dieta hospitalar. Revista de Nutrição, Campinas, 16(1):127-134 jan./mar., 2003.

SVS - Secretaria de vigilância em saúde- Vigilância epidemiológica das doenças transmitidas por alimentos no Brasil Boletim Eletrônico Epidemiológico 1999-2004, ano 5, número 6, 2005. 